\title{
Experiencias de la aplicación de las plusvalías municipales en Colombia

\author{
Municipal plus Value Application's Experiences \\ in Colombia
}

Jaime Silva Herrera*

\section{Resumen}

Los municipios desarrollan una amplia gama de políticas fiscales o regulatorias inspiradas en la idea de que el incremento en el valor de la tierra puede ser utilizado en beneficio de la comunidad, por medio de la aplicación del efecto plusvalía municipal. Este artículo presenta, en su primera parte, una corta reseña de los instrumentos de captura de plusvalías desarrollados en Colom bia; en la segunda, el doble juego en el que incurre la participación en plusvalía, y en la tercera, los pasos que se deben seguir para conseguir el objetivo final.

Palabras clave: Plusvalía municipal, Urbanismo, Valorización municipal, Impuestos, Planificación fiscal.

\footnotetext{
Docente e investigador del Centro de Investigación y Desarrollo en Información Geográfica - CIAF. MSc. en Planificación y Administración del Desarrollo Regional de la Universidad de los Andes de Colombia. Correo e.: jsilva@igac.gov.co
} 


\section{Abstract}

A wide range of property tax or regulatory policies are developed by some Municipalities based upon the idea that the increase in the land value can be used in the community's behalf, by applying the municipal value added tax. This article presents as a first resort a short review about the value added capture, developed in Colombia. As second resort, the double role played by the value added. Thirdly, it presents steps that must be taken in order to obtain the final objective.

Key words: Municipal value added, Urbanism, Taxes, Fiscal planning. 


\section{Introducción}

Los instrumentos de captura de plusvalía, aunque difíciles de aplicar, son ampliamente reconocidos como mecanismos beneficiosos de planificación fiscal. En América Latina, Colombia se ha destacado por su larga y particular tradición de institucionalización de la captura de plusvalías mediante la contribución de valorización (una especie de tasación especial) y la contribución de desarrollo municipal (Ley 9 de 1989), que antecedió al actual instrumento de participación en plusvalías.

Desde 1921, año de introducción de la primera de estas leyes, Colombia ha desarrollado una cultura fiscal en la cual los ciudadanos son conscientes de los instrumentos de captura de plusvalía y los aceptan como mecanismo legítimo de recaudación de ingresos. Como ejemplo, en 1968 (en su época de mayor uso), la contribución de valorización representó el $16 \%$ de los ingresos municipales en Bogotá y aproximadamente el $56 \%$ en Medellín; a principio de la década de los ochenta, del siglo $\mathrm{xx}$, recaudó un $30 \%$ de los ingresos totales en Cali. No obstante, debido a que el suelo aún desempeña un papel importante como defensa contra la inflación en países como Colombia -donde los mercados de capital no están muy desarrollados-, la puesta en práctica de tales instrumentos sigue enfrentando una fuerte resistencia política por parte de muchos y variados grupos de interés, desde propietarios y promotores poderosos hasta familias de bajos y medianos recursos, para quienes la tierra es una importante fuente de ahorros.

Sobre la base de esta experiencia, la Ley 388 de 1997, que creó la participación en plusvalías, decreta que todas las municipalidades deben diseñar y aprobar un Plan de Ordenamiento Territorial y adoptar la plusvalía como una de las fuentes principales de ingresos del plan. Lo recaudado por concepto de plusvalías deberá utilizarse principalmente para la provisión de infraestructura y viviendas sociales a vecindades pobremente dotadas de servicios públicos, así como para obras públicas de interés general.

La participación en plusvalías se basa en el derecho público y legítimo de participar en la captación de los aumentos del valor de la tierra generados por acciones administrativas, como cambios en zonificación o densidad; aumentos que pueden significar ganancias sustanciales para el propietario de la tierra. Es importante notar que este instrumento no es un impuesto, ni tampoco una contribución o tarifa, sino más bien un derecho de la comunidad a "participar" de los beneficios resultantes de las funciones gubernamentales orientadas a mejorar el desarrollo urbano. La Ley 388 y sus decretos acompañantes definen los parámetros generales para utilizar las plusvalías, pero se requiere que las municipalidades determinen sus procedimientos específicos. Sin embargo, a muchos al- 
caldes y funcionarios públicos les preocupan las ambigüedades de la ley y les está costando el proceso de su aplicación, así como la del instrumento de plusvalías.

\section{Enfoque}

Es importante entender que la participación en plusvalía no es solamente un recurso fiscal para el funcionamiento del desarrollo urbano, sino, ante todo, un poderoso instrumento de gestión para el ordenamiento del territorio en cumplimiento de la función pública del urbanismo, de acuerdo con los principios que lo regulan, a saber: la función social y ecológica de la propiedad, la prevalencia del interés general sobre el particular y la distribución equitativa de cargas y beneficios acarreados por los procesos de apropiación, uso y transformación del territorio (ver artículos 2 y 30 de la Ley 388/97).

La participación queda convenientemente incluida como instrumento de gestión urbanística en el capítulo III de la ley. Previamente se estatuye la Función Pública del Urbanismo (artículo 3) y se definen las Acciones Urbanisticas que en ejercicio de esta potestad puede ejecutar la administración municipal (artículo 8).

En el numeral 10 del artículo 13 se dispone, entre otros, que el componente urbano del Plan de Ordenamiento deberá contener "la definición de los procedimientos e instrumentos de gestión y actuación urba- nística requeridos para la administración y ejecución de las políticas y decisiones adoptadas, así como los criterios generales para su conveniente aplicación [...], incluida la adopción de los instrumentos para financiar el desarrollo urbano, tales como la participación municipal o distrital en la plusvalía”.

A continuación, el artículo 15 especifica las acciones y actuaciones urbanísticas que los planes deberán contemplar, y en el numeral 2 de dicho artículo, referido a las Normas Urbanisticas Generales, señala que "estas otorgan derechos e imponen obligaciones urbanísticas a los propietarios de los terrenos y a sus constructores, conjuntamente con la especificación de los instrumentos que se emplearán para que contribuyan eficazmente a los objetivos de desarrollo urbano y sufragar los costos que implica tal definición de derechos y obligaciones [negrilla mía].

En adelante, la ley vincula siempre, de manera muy estrecha, los instrumentos de financiamiento previstos para la ejecución del Plan -entre los cuales se sobreentiende que está incluida la participación- con los demás instrumentos de planeamiento y actuación que desarrollan las normas generales: se mencionan los planes parciales, las unidades de actuación y otras operaciones, como macroproyectos urbanos, algunos de los cuales pueden regularse por medio de normas complementarias. 
Así, por ejemplo, en el artículo 19, sobre planes parciales, se especifica que deberán incluir "los instrumentos mediante los cuales se desarrollan y complementan las disposiciones de los Planes de Ordenamiento para áreas determinadas del suelo urbano y para las áreas incluidas en el suelo de expansión urbana, además de las que deban desarrollarse mediante unidades de actuación urbanística, macroproyectos $\mathrm{u}$ otras actuaciones urbanas especiales, de acuerdo con las autorizaciones emanadas de las normas urbanísticas generales". Se dispone allí que se debe contemplar la delimitación y características del área de la operación urbana, la definición de usos e intensidades de ocupación y construcción del suelo, el trazado y las características del espacio público, las vías, las redes de servicios públicos y los equipamientos, y, por último, vinculado a todo lo anterior, se exige la adopción de los instrumentos del manejo del suelo (numeral 6) entre los cuales menciona la captación de plusvalías y el reparto de cargas y beneficios.

En todos los casos, la liquidación del monto de la participación y su concomitante indexación debe interpretarse como un poderoso recurso para prevenir, al menos en parte, la indebida especulación con los suelos urbanos en detrimento de la eficiencia de los inversionistas y de la capacidad adquisitiva de los demandantes o como herramienta para asegurar el adecuado disfrute del espacio público para todos los ciudadanos, que se relaciona con el cumplimiento de la función social y ecológica de la propiedad; todo esto sin perjuicio de su función obvia, como instrumento de reparto equitativo de las cargas y beneficios acarreados por el proceso de urbanización.

\section{Actores y roles}

Una vez visto el doble juego en el que incurre la participación en plusvalía -al constituir, por un lado, un importante instrumento para la eficaz gestión de las políticas adoptadas en los planes de ordenamiento territorial, y representar, por el otro, un recurso fiscal llamado a tener una importancia creciente en las ciudades intermedias y mayores, en cuanto instrumento para financiar el desarrollo urbano-, veremos el papel que desempeñan los principales actores dentro de la participación y las experiencias que han dejado en Colombia a lo largo de estos cinco años de aplicación de dicho instrumento.

Los actores que a mi juicio hacen parte y desempeñan una tarea importante dentro del proceso de captación de plusvalías municipales son: el Estado, representado directamente por el municipio; el ejecutante de los avalúos (IGAC, Lonjas Inmobiliarias, Catastros independientes); los catastros, encabezados por el Agustín Codazzi; el Departamento Administrativo de Catastro Distrital; los catastros de Cali, Antioquia y Medellín; las oficinas de Registro de Instrumentos Públicos y, 
obviamente, la comunidad, que a su vez se subdivide en actores tales como los propietarios de los terrenos, los promotores inmobiliarios, los comerciantes y los ambientalistas, entre otros. Todos los anteriores actores observan la aplicación de la participación en plusvalía desde sus intereses $y$, obviamente, dependiendo de ello así se comportan.

Veamos ahora el papel que ha desempeñado cada uno de ellos y las experiencias que ha dejado este importante proceso.

El municipio aparece como un gran protagonista directo de la participación en plusvalía, es el ente que debe planificar muy bien las acciones por seguir, antes, durante y después del cálculo de la participación en plusvalía. Debe estar representado por el Alcalde, la oficina de Planeación Municipal, el Concejo Municipal y Tesorería Municipal, entre otros.

En Colombia son realmente pocos los municipios que han cumplido el proceso completo de la participación en plusvalía, esto se debe fundamentalmente a un desconocimiento del tema.

Las oficinas de Planeación Municipal, que son las llamadas a liderar el proceso, no lo han hecho con lujo de detalles, a excepción del Departamento Administrativo de Planeación Distrital de Bogotá. Este ha formado una eficaz llave con el Departamento Administrativo de Catastro Distrital, que ha llevado a Bogotá a ser uno de los municipios modelo en Colombia en materia de aplicación de este gravamen. Sopó (Cundinamarca) también cumplió exitosamente con todo el proceso $y$ hoy se ve beneficiado por el buen recaudo efectuado.

En términos generales, el municipio debe cumplir unos pasos en el proceso de participación en plusvalía, que analizaremos a continuación, al igual que la participación de cada actor dentro del proceso:

1. Expedición del acto administrativo que determina los hechos generadores de plusvalía (Acuerdo POT).

2. Adopción del acuerdo general por el cual se establecen las normas para la aplicación de la participación en la plusvalía en el municipio en cuestión.

3. Expedición de actos administrativos que concreten los hechos generadores en cuanto instrumentos que desarrollan o complementan el POT.

4. Determinación y delimitación de las áreas potencialmente objeto de la participación en plusvalía.

Con respecto a este numeral, es importante destacar que se han encontrado serias inconsistencias de carácter técnico, pues los polígonos resultantes no obedecen a la realidad de cambio de norma, sino a otras circunstancias que lo que hacen es desvirtuar y provocar 
grandes errores, especialmente para el encargado de efectuar los avalúos, quien ha confiado de antemano en la calidad de este trabajo preliminar.

Este punto es, quizá, el más neurálgico, por lo que se considera debe ser objeto del mayor control por parte del municipio.

\section{Solicitud del alcalde para la ejecu- ción de los avalúos para plusvalía.}

En este aspecto se han detectado también serias inconsistencias, que tienen que ver directamente con las solicitudes fuera de tiempo que han efectuado muchos alcaldes tanto al IGAC como a catastros independientes y a la Lonja de avaluadores. Se olvida que la participación en plusvalía se causa en el momento en que entra en vigencia el plan de ordenamiento territorial o los instrumentos que lo desarrollan y concretan los hechos generadores.

Otro problema detectado hasta el momento es que los municipios no poseen la cartografía necesaria para efectuar esta clase de estudios, es decir, a escalas 1:1000, 1:2000. Hay que entender que cualquier predio que se deje por fuera o que sea involucrado sin serlo puede ocasionar graves problemas, tanto jurídicos como técnicos, que pueden comprometer seriamente al municipio, a la entidad ejecutora de los avalúos y a los mismos propietarios.

Aunque no se hace imprescindible en una primera etapa tener un Sistema de
Información Geográfica instalado y funcionando dentro del respectivo municipio, se observa que esta herramienta es indispensable en actividades como la elaboración del mismo plano de hechos generadores de plusvalía (municipio) y, más adelante, en los diseños de zonas homogéneas físicas y geoeconómicas (perito).

\section{Cálculo del efecto plusvalía según clase o tipo del hecho generador.}

A estas instancias del proceso, entra en juego un importante actor: el ejecutor de los avalúos para plusvalía, que puede ser el Instituto Geográfico Agustín Codazzi, los catastros independientes de Bogotá, Cali, Medellín y Antioquia o la Lonja de avaluadores.

Para efectuar su trabajo, este actor depende básicamente de la calidad de la información que le sea entregada por el respectivo municipio.

Como experiencia es importante destacar que el ejecutor de los avalúos (cualquiera de los actores nombrados) deberá realizar previamente las siguientes actividades:

a. Determinar muy bien que la solicitud proveniente del Alcalde esté verdaderamente contenida dentro de los tiempos de ley; de lo contrario se hace prudente no dar inicio a los trabajos.

b. Conocer bien si lo que dice tener el municipio en lo referente a cartografía cumple con los parámetros 
técnicos para dar inicio a la actividad. Aquí también se hace importante el actor, así no sea función directa suya validar el plano de hechos generadores de plusvalía; para ello las oficinas de Planeación Municipal se convierten en una eficaz ayuda. Recordemos que el plano de hechos generadores de plusvalía contiene los predios que seguramente van a ser afectados por el gravamen. Del número de ellos depende directamente el costo, tanto en tiempo como en plata del proyecto; cualquier discrepancia al respecto puede resultar costosa para los actores.

c. Se hace necesario, entonces, que el ejecutante de los avalúos no firme ningún convenio, contrato o cualquier otro documento jurídico que lo comprometa directamente, hasta no tener plena seguridad de que la información suministrada o por suministrar es confiable para desarrollar el estudio. Se puede pensar al respecto que previo a la firma de algún documento que comprometa al ejecutor de los avalúos se puede negociar con el respectivo municipio para efectuar conjuntamente una valuación detallada sobre todas las actividades anteriormente denotadas.

d. En lo referente al actor principal de este numeral hay que tener en cuenta su idoneidad y ética, no exclusivamente para realizar los avalúos, sino que su conocimiento debe llegar a campos como el jurídico y el ordenamiento territorial, obviamente sobre el tema de la plusvalía. Al respecto, como la ley fija un término de 60 días hábiles para realizar el cálculo de los avalúos, y la zona por estudiar involucra muchos predios (piense en una ciudad como Bogotá), se necesitará muchas personas capacitadas para efectuar el proyecto; de su integración, y no su individualización, depende en definitiva la suerte técnica y jurídica del estudio.

Considero que en Colombia, salvo pocas excepciones, se sigue cayendo en la falta de planificación para las anteriores actividades.

e. El actor de este numeral debe necesariamente enfrentarse a otro actor primordial, que es el ente catastral que ejerza jurisdicción sobre el municipio en cuestión. La información catastral, más exactamente el reconocimiento predial de la zona de estudio, debe estar actualizada, de lo contrario el proyecto sufrirá graves consecuencias en el resultado final. El grado de la desactualización de la información catastral debe ser un punto por evaluar, clave para el proceso.

f. Tanto este actor como los demás que intervienen en el proceso tendrán que acudir a una normatividad vigente sobre plusvalía que todavía no ha llenado ciertos vacíos, sobre todo en el hecho generador de plusvalía referente al cálculo por efecto de un mayor aprovechamiento del suelo en edificación; al respecto, el Ministerio de Hacienda y Crédito Público, el Departamento Nacional de Planeación, el Instituto Geográfico Agustín Codazzi y el Ministerio del Ambiente, Vivienda y De- 
sarrollo están analizando fórmulas que contribuyan a enriquecer el proceso en este aspecto. La falta de claridad en algunas normas sobre plusvalía deja vacíos técnicos $\mathrm{y}$, por ende, grandes dificultades para aplicar exitosamente la plusvalía en Colombia.

\section{Liquidación del monto de la parti- cipación.}

El municipio debe planificar esta actividad, en el mejor de los casos, con la consecución de programas especiales que ayuden a agilizar la culminación del proceso.

Se nota todavía falta de planificación por parte de los municipios en este ítem.

\section{Notificación y divulgación del efecto plusvalía.}

Esta parte jurídica dentro del proceso adquiere una gran importancia, y de no cumplirse puede ser nefasto, pues queda cerca de la impugnación por parte de cualquier actor que participe en el estudio.

\section{Inscripción del gravamen en los folios de matrícula inmobiliaria.}

Expedido, notificado y debidamente divulgado el acto administrativo a través del cual se liquida la participación en plusvalía, el Alcalde municipal oficiará a la Oficina de Registro de Instrumentos Públicos (nuevo actor dentro del proceso) de la localidad respectiva, para que de conformidad con lo ordenado por el Artículo 81 de la Ley 388 de 1997, en un plazo no mayor a dos meses, inscriba en el folio de matrícula inmobiliaria de cada uno de los predios de las zonas correspondientes la obligación de cancelar el monto de la participación en plusvalía.

En este aspecto hasta el momento no se ha escuchado queja alguna.

\section{Actor comunidad (propietarios de los predios que han entrado en plusvalía).}

Es el actor sobre el cual recae directamente la responsabilidad de pagar el gravamen; por lo general no acompaña directamente el proceso y es sorprendido al final, cuando se han agotado los términos para interponer los recursos. Dentro de las experiencias que se han reunido en este proceso de la aplicación del gravamen plusvalía se tienen ciertas apreciaciones de este importante actor, veamos las principales:

- Una fuente continua de confusión y malentendidos; se refiere a la eficacia del cálculo del incremento en el valor del suelo. ¿Puede o debe implementarse este cálculo en los casos en que, debido a una recesión económica generalizada, los valores del suelo estén supuestamente en declive? Si el propietario pierde dinero al vender la tierra, o si no está desarrollando sus propiedades en absoluto, entonces 
sencillamente no habrá plusvalías disponibles para la administración local. Teóricamente bastaría con hacer una distinción entre los efectos generadores (acciones administrativas) y las tendencias en los mercados de tierras. Sin embargo, tal como está sucediendo actualmente en Colombia, en la práctica es fácil entender que los instrumentos de captura de plusvalías son más poderosos y políticamente aceptables durante los períodos de ascenso de los ciclos de precios del suelo que durante los períodos de descenso.

- Las connotaciones políticas del tema se ponen de relieve si se consideran las sustanciales carteras de tierra normalmente apartadas por los promotores para fines de planificación estratégica e incluso de especulación. En efecto, muy a menudo los planificadores urbanos se ven obligados a ser más flexibles y a aflojar los reglamentos urbanísticos a fin de motivar a los promotores durante las épocas de recesión. Claro está que esta presión por parte de los promotores podría sencillamente ser un intento de recuperar pérdidas incurridas por las decisiones equivocadas sobre inversiones en el pasado.

- Algunas veces los promotores se quejan de que la municipalidad está fijando una tarifa de plusvalía demasiado alta en tiempos de economía deficiente, cuando la recesión puede desalentar las inversiones futuras en mejoras de construcción. Sin embargo, la experiencia con la contribución de la valorización ofrece un contraargumento, sugiriendo que si la cantidad de plusvalías generadas por el cambio en el uso de la tierra se considera sobrevaluada, significa que el cambio carece de una buena razón costo/eficacia y, por tanto, no debería proponerse. Otra posibilidad es que quizá se cometió un error en los estudios o cálculos de viabilidad.

- Por encima de estas dificultades prácticas, la ley impone ciertos requisitos de aplicación que afectan su operación, como la necesidad de notificar directamente al propietario que su propiedad está sujeta a obligaciones por plusvalías. ¿Debería esta responsabilidad correr por cuenta de la administración pública o del propietario? Existen también dificultades legales respecto a cuándo se deben cobrar las plusvalías al propietario (¿durante la liquidación de las propiedades?, ¿cuando el propietario solicite la licencia de conversión del uso del suelo?). De la misma manera, si un área que se va a densificar (o sufrir cualquier cambio de zonificación) recibió una infraestructura adicional por la cual se le impuso la contribución de valorización, el propietario estaría sujeto a una doble tributación, algo que sin duda constituiría una fuente de malestar. Tal como lo establece la nueva ley, la contribución de valorización es independiente de las plusvalías, lo cual es importante debido a la opción existente de calcular y cobrar las "plusvalías por las obras públicas designadas por el Plan de Ordenamiento Territorial (POT)". 


\section{Conclusiones}

La participación en plusvalías se basa en el derecho público y legítimo de participar en la captación de los aumentos del valor de la tierra generados por acciones administrativas, como cambios en zonificación o densidad, que pueden representar ganancias sustanciales para el propietario de la tierra.

La participación en plusvalías juega un doble papel en los sistemas de planeación municipal: por un lado, constituye un instrumento importante para la gestión de las políticas adoptadas en los planes de ordenamiento territorial; por el otro, representa un recurso fiscal, especialmente para las ciudades intermedias y mayores, en cuanto es instrumento para financiar el desarrollo urbano.

Los municipios son los actores primordiales dentro del proceso de captación de plusvalía; estos deben proporcionar la información pertinente para el estudio, solicitar los avalúos a tiempo y de acuerdo con las normas vigente y cumplir con la entrega de cartografía de la zona de estudio en escalas adecuadas para el estudio 1:1000, 1:2000. Deben velar por la calidad y pertinencia del plano de hechos generadores de plusvalía.

Los ejecutantes de los avalúos para plusvalías deben estar atentos a validar la información que el municipio entregue $y$, si es el caso, no dar inicio a ninguna actividad si falta información o es deficiente.
La entidad ejecutora de los avalúos debe contratar o designar gente idónea en los temas de avalúos, catastro, ordenamiento territorial y sistemas de información geográfica.

Se hace vital que la información catastral esté completamente actualizada, de lo contrario el proceso sufrirá serios problemas tanto técnicos como jurídicos.

Es importante que la normatividad sobre plusvalía sea estandarizada; para ello, tanto el Departamento Nacional de Planeación y el Ministerio del Medio Ambiente, Vivienda y Desarrollo Rural, como el IGAC, deben unir esfuerzos para que la normatividad sea clara y posible de aplicar.

La comunidad, representada específicamente por los dueños de los predios susceptibles del gravamen, deberá estar pendiente de todo el proceso, especialmente en la fase de difusión, para que, en caso de no estar conforme con el resultado, pueda solicitar el recurso a tiempo, tal como lo estipula la ley.

Al igual que la elaboración de los planes de ordenamiento territorial ha traído beneficios generales a los municipios colombianos, se espera que el gravamen plusvalía pueda contribuir para que los recursos que se capten por este medio sirvan para mejorar la calidad de vida de los habitantes del municipio. 


\section{Bibliografía}

Camacho Montoya, Álvaro (2003): La plusvalía: un nuevo tributo inmobiliario. Bogotá D.C.

Lincoln Institute of Land Police Publications (1999): Taller La Recuperación de Plusvalías "Socialmente Creadas" en Colombia. Bogotá, D.C.

Fecha de recepción: agosto 2005

Fecha de aprobación: octubre de 2005

298 Jaime Silva Herrera 